\title{
Ants contribute to pollination but not to reproduction in a rare calcareous grassland forb
}

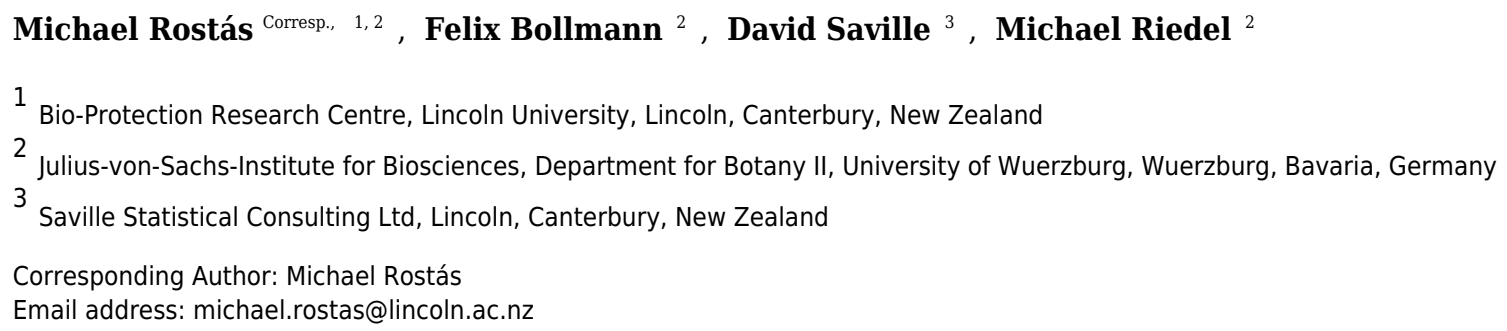

The number of plants pollinated by ants is surprisingly low given the abundance of ants and the fact that they are common visitors of angiosperms. Generally ants are considered as nectar robbers that do not provide pollination service. We studied the pollination system of the endangered dry grassland forb Euphorbia seguieriana and found two ant species to be the most frequent visitors of its flowers. Workers of Formica cunicularia carried five times more pollen than smaller Tapinoma erraticum individuals, but significantly more viable pollen was recovered from the latter. Overall, the viability of pollen on ant cuticles was significantly lower $(p<0.001)$ - presumably an antibiotic effect of the metapleural gland secretion. A marking experiment suggested that ants were unlikely to facilitate outcrossing as workers repeatedly returned to the same individual plant. In open pollinated plants and when access was given exclusively to flying insects, fruit set was nearly $100 \%$. In plants visited by ants only, roughly one third of flowers set fruit, and almost none set fruit when all insects were excluded. The germination rate of seeds from flowers pollinated by flying insects was $31 \pm 7 \%$ in contrast to $1 \pm 1 \%$ resulting from ant pollination. We conclude that inbreeding depression may be responsible for the very low germination rate in ant pollinated flowers and that ants, although the most frequent visitors, play a negligible or even deleterious role in the reproduction of $E$. seguieriana. Our study reiterates the need to investigate plant fitness effects beyond seed set in order to confirm ant-plant mutualisms. 


\section{Ants contribute to pollination but not to reproduction in a rare}

\section{2 calcareous grassland forb}

3

4 MICHAEL ROSTÁS ${ }^{1,2}$, FELIX BOLLMANN², DAVID SAVILLE ${ }^{3}$, MICHAEL RIEDEL $^{2}$

5

$6 \quad{ }^{1}$ Bio-Protection Research Centre, Lincoln University, Lincoln 7647, New Zealand

7 2Julius-von-Sachs-Institute for Biosciences, Department for Botany II, University of Würzburg, 97082

8 Würzburg, Germany

$9 \quad{ }^{3}$ Saville Statistical Consulting Ltd, Lincoln 7640, New Zealand

10

11

12

13

14

15

16

17

18 Correspondence: M. Rostás. Fax: +643325 3864; e-mail: michael.rostas@lincoln.ac.nz 


\section{Abstract}

The number of plants pollinated by ants is surprisingly low given the abundance of ants and the fact that they are common visitors of angiosperms. Generally ants are considered as nectar robbers that do not provide pollination service. We studied the pollination system of the endangered dry grassland forb Euphorbia seguieriana and found two ant species to be the most frequent visitors of its flowers. Workers of Formica cunicularia carried five times more pollen than smaller Tapinoma erraticum individuals, but significantly more viable pollen was recovered from the latter. Overall, the viability of pollen on ant cuticles was significantly lower $(p<0.001)$ - presumably an antibiotic effect of the metapleural gland secretion. A marking experiment suggested that ants were unlikely to facilitate outcrossing as workers repeatedly returned to the same individual plant. In open pollinated plants and when access was given exclusively to flying insects, fruit set was nearly $100 \%$. In plants visited by ants only, roughly one third of flowers set fruit, and almost none set fruit when all insects were excluded. The germination rate of seeds from flowers pollinated by flying insects was $31 \pm 7 \%$ in contrast to $1 \pm 1 \%$ resulting from ant pollination. We conclude that inbreeding depression may be responsible for the very low germination rate in ant pollinated flowers and that ants, although the most frequent visitors, play a negligible or even deleterious role in the reproduction of $E$. seguieriana. Our study reiterates the need to investigate plant fitness effects beyond seed set in order to confirm ant-plant mutualisms. 
41 Ants are frequent visitors of angiosperms, and although they may be involved in mutualistic interactions

42 that benefit the plant such as seed dispersal or the removal of herbivorous insects, ants have

43 traditionally been regarded as poor pollinators (Beattie 2006; Rico-Gray and Oliveira 2007; Rostás and

44 Tautz 2011). Accordingly, a relatively small number of ca. 40 supported cases of ant pollination have

45 been documented so far, mostly within the last two decades (de Vega and Gómez 2014).

Several traits associated with ants are held responsible for their insignificant or even detrimental role in plant reproduction. The main arguments against ants as vectors as facilitators of pollination in general are their foraging patterns and the presence of metapleural gland secretion on their integument. This secretion protects the ants from infection by microorganisms but may inadvertently have negative effects on the viability of pollen, except in some plants where ants are the primary pollinators (Beattie et al. 1984; Beattie et al. 1986; de Vega et al. 2009). Dutton and Frederickson (2012) compared several ant and plant species from temperate and tropical habitats and found reduced pollen germination in all cases with more pronounced effects in tropical ants, where microbes are expected to impose stronger selection for antibiotic defences.

Ant workers are wingless and small and it has been suggested that in many plants they do not carry pollen far enough for outcrossing and continuously return to the same individual plant for nectar. This Ortstreue (Hölldobler and Wilson 1990) results predominantly in within-plant pollen movement and hence in geitonogamy. Not surprisingly, the large majority of ant pollinated plants listed in the latest review by de Vega and Gómez (2014) are considered to be self-compatible and would therefore be less

60 affected by geitonogamy than obligate outcrossing species. Self-pollination can lead to the abortion of seeds in outcrossing plants but even in self-compatible species, inbred seeds may have lower germination rates and higher seedling mortality (Baskin and Baskin 2015; Gómez 2000). However, this 
64 offspring viability (but see Blancafort and Gómez (2005) and de Vega et al. (2009) for other measures of 65 seed viability).

66 Ant pollinated species are often characterised by small, open flowers and by inhabiting dry and/or alpine

67 habitats in which ants are generally abundant (de Vega et al. 2009; Gómez et al. 1996; Hickman 1974).

68 Indeed, this quantitative aspect of ant pollination has been identified as a crucial component, where

69 numerous transfers of (often inviable) pollen grains to stigmata by many individuals can compensate for

70 the vector's inefficiency (Gómez and Zamora 1992). The easily accessible nectaries of Euphorbia L.

71 species (Euphorbiaceae) for instance are very frequently visited by ants and an ant role in pollination has

72 been suggested for some members of the genus (Araf et al. 2010; Blancafort and Gómez 2005; Schürch 73 et al. 2000).

74 In the present study we have analysed the pollination system of the endangered forb E. seguieriana. An 75 understanding of the pollination system of rare plant species is crucial for their conservation, in 76 particular in species with a high dependency on outcrossing as pollinator conservation may play a key 77 role in management strategies (Carvalheiro et al. 2008). Specifically, we assessed the (1) frequency of 78 ants as flower visitors, (2) pollen load and pollen grain viability, (3) the foraging behaviour of ants and 79 hence the likelihood of outcrossing, (4) female fertility as well as (5) the germination rate of seeds. Our 80 results suggest that although ants appear to play a role as pollinators of E. seguieriana, they do not 81 contribute to the plant's sexual reproduction.

\section{Materials and methods}

84 Study system 
Siberian spurge, Euphorbia seguieriana subsp. seguieriana Necker (Malpighiales: Euphorbiaceae), is a perennial forb, native to Eurasia. In Germany the species inhabits dry, calcareous or sandy grasslands, mainly in the basins of the rivers Rhine, Main, Ems, Nahe, Mosel and Unstrut (Senghas and Seybold 2003). The plant is considered a threatened species and listed in the Red List of the German Federal Agency for Nature Conservation. Siberian spurge typically grows $15-60 \mathrm{~cm}$ tall with numerous stems branched from its base. It flowers from June until August and is protogynous, in which the stigma is receptive before the pollen is shed. The inflorescence is a typical cyathium, consisting of strongly reduced male and female flowers, bearing sickle shaped nectaries that offer easily accessible nectar. Functionally the cyathium can be considered as hermaphroditic flower and for simplicity will be termed "flower" here. The capsule fruit is on average $2.3 \mathrm{~mm}$ long and bears three seeds which are shed when the capsule dehisces (retrieved from www.floraweb.de, 2017).

Two ant species were observed to visit the nectaries of E. seguieriana. Formica cunicularia Latreille (Hymenoptera: Formicidae; Fig. 1) is a moderately thermophilic species and common throughout Europe where it prefers semidry habitats with a developed herb layer (Seifert and Schultz 2009). Workers are 4.0-6.5 $\mathrm{mm}$ long and forage for nectar and honeydew; the species is also zoophagous (Collingwood 1979; Novgorodova 2015). Tapinoma erraticum Latreille (Hymenoptera: Formicidae) is a small black ant (2.6-4.2 $\mathrm{mm}$ ) which lives in diverse habitats, including xerothermic grassland. The species is present in most of Europe; it has a carnivorous and aphidicolous lifestyle and feeds on nectar (Collingwood 1979). The clypeal cleft is considered a morphological adaptation for exploiting liquids hidden in narrow spaces such as floral nectars (Seifert 2016).

The field site was a dry calcareous grassland $\left(480 \mathrm{~m}^{2}\right)$ characteristic for the region of Lower Franconia. The site was situated within the boundaries of the botanical garden of the University of Würzburg, Germany $\left(49^{\circ} 45^{\prime} 54.34 " \mathrm{~N}, 9^{\circ} 55^{\prime} 48.28^{\prime \prime} \mathrm{E}, 214 \mathrm{~m}\right.$ above sea level), located on a slope of the Main river valley. The study population of E. seguieriana consisted of ca. 300 individuals and was chosen for its 
109

110

111

112 113 from 2006-2008.

114

115

116

117

118

119

120

121

122

123

124

125

126

127

128

129

130

ease of access and to limit any negative impact by the experimenter on protected areas. Further populations of E. seguieriana exist on calcareous grassland sites along the Main river, which are integral nature reserves (e.g. Grainberg-Kalbenstein, Höhfeldplatte and Scharlachberg) of international significance with a high diversity of endemic and endangered species. Experiments were carried out

\section{Frequency of ants as flower visitors}

The frequency of ants and other insects visiting E. seguieriana flowers was assessed during a period of 10 observation days in August 2007. Each observation unit consisted of a bundle of rays with approximately 125 cyathia. Twenty of these floral units were observed twice daily (10:00-11:00 and 15:00-16:00) for 1 minute per unit and all insects drinking nectar or carrying pollen were recorded. Observations were made at a distance of $80 \mathrm{~cm}$ from the inflorescences to avoid disturbance. Specimens of flower visitors were caught with a net after the observation period. Ants were determined to species level (Seifert 1984; Seifert 1996) while flying insects were identified to the level of family (Schaefer 2000). Voucher specimens of flower visiting ant species were conserved in $70 \%$ ethanol and stored in the collection of the Department of Botany, University of Würzburg. The weather during each observation was categorized as sunny, cloudy or rainy.

\section{Foraging behaviour of ants}

The behaviour of individual T. erraticum and F. cunicularia ants on E. seguieriana flowers was compared to obtain more information about their role as potential pollinators. Two to three neighbouring stems of a single plant were marked with a small piece of tape to form one observation unit. Each observation 
131 unit consisted of 100 cyathia. Depending on plant size, one or two observation units per plant were

132 designated. Individual ants were observed on 20 units distributed over 13 randomly selected plants for a 133 period of 5 minutes and at a distance of $80 \mathrm{~cm}$ to avoid disturbance. The software The Observer 5.0.25

134 (Noldus Information Technology) was used to record numbers of visited cyathia, time spent consuming

135 nectar and frequency of moving between stems of the same plant.

136 In a second experiment, the potential for outcrossing was assessed by recording whether individual ants

137 exclusively foraged on flowers of the same individual $E$. seguieriana plant or whether other $E$. 138 seguieriana in the vicinity were also visited. Six plants were randomly selected and all foraging ants were 139 carefully marked (paint marker, Edding 750) with a colour dot on the thorax while walking on the flower $140(\mathrm{n}=290 \mathrm{~T}$. erraticum, $\mathrm{n}=120 \mathrm{~F}$. cunicularia). A different colour was used for each of the six plants. The 141 following five days, all E. seguieriana plants at the field site (approx. 300) were checked daily for the 142 presence of marked ants during 10:00 - 14:00. The presence of colour-coded ants on the six 143 experimental spurge plants and on other, unmarked E. seguieriana was recorded.

146 The quality of pollen attached to the cuticles of foraging ants was assessed using the fluorochromatic 147 procedure (FCR) according to (Heslop-Harrison et al. 1984). Ants foraging on E. seguieriana and carrying 148 pollen were allowed to walk onto a petri dish with polytetrafluoroethylene (Fluon; Asahi Glass Co., Ltd.) 149 treated sidewalls to prevent escape and a microscope slide with a drop of FCR solution placed in the centre of the dish. The FCR solution was freshly prepared each day by dropwise adding fluorescein diacetate in acetone $\left(2 \mathrm{mg} \mathrm{ml}^{-1}\right)$ to $2 \mathrm{ml}$ of a $0.6 \mathrm{M}$ sucrose solution until the solution became slightly cloudy. The trapped ant was held by the legs with insect handling tweezers, placed immediately into the 
154 used for each ant. Four to five slides were prepared at a time and immediately taken to the laboratory

155 for testing of fluorescent and non-fluorescent pollen numbers using a fluorescence microscope (Leica

156 DMR). The pollen load of 30 ants per species was assessed. As a control, pollen was collected directly

157 from E. seguieriana anthers and tested as described above ( $n=23$ plants).

An exclusion experiment similar to (Schürch et al. 2000) was carried out to assess the role of ants as pollinators. Plants in the bud stage were randomly selected and each plant was assigned to one of the following treatments $(n=10)$ : (i) All visitors - plants were not manipulated, therefore all insects could visit flowers, (ii) No visitors - Flowers were enclosed by tying mosquito netting fabric around the stems,

(iii) Winged only - flying insects could visit the flowers but crawling insects were excluded by driving a plastic cylinder (diameter: $24 \mathrm{~cm}$, height: $24 \mathrm{~cm}$ ) into the ground that surrounded the plant. The outer cylinder wall was painted with an insect trapping adhesive (Raupenleim grün, Schacht GmbH \& Co. KG, mosquito netting fabric and bamboo stick frames. The cage was attached around a cylinder as in (iii) but a $5 \mathrm{~cm}$ gap between ground and cylinder rim was maintained to allow ants to access the flowers. Experimental plants were checked daily to ensure that the correct insect groups were excluded. In rare cases where non-target species were found, these were removed immediately. A subsample of five

172 stems per plant (randomly selected and marked before the experiment) was assessed by counting the numbers of formed fruit capsules and unfertilized female flowers.

174 The following year the experiment was repeated with the treatments 'Winged only' and 'Ants only' $(n=$ 175 9-10). Five stems per plant with approximately similar numbers of cyathia were marked. As soon as the capsules started to ripen and dry out, large empty tea filters (Cilia, Melitta Group Bentz KG, Minden) 
177 were tied around the stems. Fruit capsules were left to dehisce and the harvested seeds were then

178 stored for 4 weeks at $10{ }^{\circ} \mathrm{C}$ in a sealed paper bag. Thirty seeds from each plant were sown into trays

179 with seed mix and kept in an open greenhouse tunnel to germinate. After 10 weeks the number of

180 established seedlings was counted.

For each of the individual plants, the numbers of visits by each 'species' (two ant species, F. cunicularia and T. erraticum, both individually and as a total of all ants, and Winged insects) were totalled over the 10 sampling days and over both morning and afternoon samplings. This total number of visits for each plant and species (and ants as a whole) was then square root transformed to convert it from a Poissondistributed variable to a variable with an approximate Normal distribution. Four differencing variables were calculated for each plant: (a) visits by F. cunicularia vs. T. erraticum, (b) visits by F. cunicularia vs. Winged insects, (c) visits by T. erraticum vs. Winged insects, (d) visits by ants (in total) vs. Winged insects. For each of the four variables, a 95\% confidence interval (C.I.) for the true difference in (square root of) number of visits between the two species was calculated. If this $95 \%$ C.I. did not include zero, this meant there was a $5 \%$ significant difference between the two species in visitation rate. In such a case, the level of significance of the difference was determined by calculating the $99 \%$ C.I., $99.9 \%$ C.I., and so on. Furthermore, for each of the 20 half-days (10 sampling days $\mathrm{x}$ morning/afternoon), the number of visits for each half-day and species (and the three species as a whole) was totalled over the 20 plants and square root transformed. These variables were then input into an analysis of covariance (ANCOVA) routine, with treatment terms being sampling day + morning/afternoon (main effects only) and covariate weather (with $0=$ rainy, $3=$ cloudy and $4=$ sunny). The above four differencing variables were also calculated for each half-day and subjected to the same statistical analysis. 
200 The time ants spent collecting nectar, the frequency of switching between stems, the viability of pollen

201 and the germination rate of seeds were analysed by Mann-Whitney $U$ tests. A Kruskal-Wallis ANOVA was

202 used to determine differences in viability of pollen recovered from both ant species and the control.

203 For the first exclusion experiment overall analysis of variance was considered unsuitable due to the

204 observed data distribution. Instead, the percentage of formed fruit capsules was calculated for each

205 experimental plant; then, the 95\% confidence interval for the true mean percentage was calculated for

206 each treatment separately. The data were treated separately since the variability varied widely

207 between the four treatments (two treatments were close to $100 \%$, one treatment was close to $0 \%$,

208 while the fourth treatment had relatively high variability).

\section{Results}

210 Ants as flower visitors

211 The two ant species that foraged on E. seguieriana accounted for $65 \%$ (F. cunicularia: $36 \%$, T. erraticum:

$21229 \%$ ) of all flower visitors and were the most frequent visitors ( $V$ (no. of ants) vs. $V$ (no. of winged insects):

$21395 \%$ C.I. $=1.867 \pm 0.595, p<0.001$, Fig. 2). The remaining $35 \%$ of nectar foraging insects were winged

214 insects of the orders Hymenoptera (Sphecoidea, Halictus) and Diptera (Conopidae, Tachinidae,

215 Syrphidae, Ceratopogonidae). A comparison of flower visitation rates showed no significant differences

216 between the three visitor groups (on the scale of $V($ total no. over 10 days): $F$. cunicularia vs. $T$.

217 erraticum: $95 \%$ C.I. $=1.100 \pm 1.399 ;$ F. cunicularia vs. winged insects: $95 \%$ C.I. $=0.203 \pm 0.643 ; T$.

218 erraticum vs. winged insects: $95 \%$ C.I. $=-0.896 \pm 0.971)$. No significant differences were also found

219 between morning (10:00 - 11:00) and afternoon (15:00 - 16:00) visitation rates in the ANCOVAs for any

220 of the eight variables (all species, individual species and pairwise combinations of species including ants

221 vs winged insects, Fig. 3a). However, flower visits correlated positively with weather for the sum of the 
222 three species $(p<0.05)$, for F. cunicularia $(p<0.10)$ and for winged insects $(p<0.01)$, Fig. 3b. Lower

223 numbers of insects were observed on rainy days and more were observed on sunny days.

Foraging behaviour of ants

226

227

228

229

230

231

232

Ants of the larger species $F$. cunicularia visited more than three times as many flowers during each observation period (Mann-Whitney $U$ test, $U=25.5, p<0.001$, Fig. 4a) but spent only half as much time collecting nectar per flower compared to individuals of T. erraticum (Mann-Whitney $U$ test, $U=154, p<$ 0.001 , Fig. 4b). F. cunicularia was also observed to switch more frequently $(1.0 \pm 0.2$ switches per observation) from one stem to another within the same plant than T. erraticum $(0.2 \pm 0.1$ switches per observation; Mann-Whitney $U$ test, $U=245, p<0.001$ ).

The marking experiment demonstrated that during a 5-day observation period both ant species consistently returned to the same individual E. seguierana plant on which they had been marked at the start of the experiment. None of the marked ants was found foraging on any other spurge plant in the study population during the daily 4-hour assessments, therefore no statistical tests were carried out. Overall more F. cunicularia than T. erraticum ants were observed foraging on the plants on which they had been first caught, despite the fact that more T. erraticum had been marked initially.

\section{Effect of ants on pollen quality}

Ants captured on E. seguieriana differed significantly in the number of pollen attached to their cuticle (Mann-Whitney $U$ test, $U=147.0, p<0.001$, Fig. 5a). On average, individuals of $F$. cunicularia had pollen loads six times higher than T. erraticum. However, in most cases (87\%) the pollen sampled from $F$. cunicularia ants did not fluoresce and was considered unviable. The average viability of pollen recovered 
244 from all $F$. cunicularia workers was therefore $8 \pm 4 \%$. In cases where recovered pollen did show

245 fluorescence (i.e zero values), the viability rate was $59 \pm 7 \%$. In T. erraticum, $43 \%$ of captured ants

246 carried viable pollen with an average viability rate of $30 \pm 7 \%$. In cases where recovered pollen did show

247 fluorescence, the viability rate was $69 \pm 8 \%$. A Mann-Whitney $U$ test indicated that numbers of viable

248 pollen carried by ants was significantly greater for $T$. erraticum than for $F$. cunicularia $(U=321, p=$

249 0.016, Fig. 5b). The fluorescence test further showed that pollen recovered from ant cuticles was less

250 viable compared to pollen collected directly from unmanipulated male flowers (viability rate: $72 \pm 4 \%$,

251 Table S4) (Kruskal-Wallis test followed by Dunn's tests, d.f. $=2, H=50.5, p<0.001, F$. cunicularia vs

252 plant: $p<0.001$, T. erraticum vs plant: $p<0.001$ ).

Effect of ants on plant reproductive success

255

256

257

258

259

260

261

262

263

264

265

266

Fruit set in E. seguieriana depended on the presence and type of insect visitors (Fig. 6). When access to plants was unrestricted for all visitors, nearly $100 \%$ of flowers (95\% C.I.: $96.6 \pm 3.5$ ) set fruit. Likewise this was found in plants pollinated exclusively by winged insects (95\% C.I.: $98.4 \pm 2.5$ ) and therefore no significant difference $(\alpha=0.05)$ in fruit set was observed between treatments 'All visitors' and 'Winged only'. Where access was allowed to ants only, the percentage of flowers turning into seed bearing fruit was $37.2 \pm 18.8 \%$ (mean and 95\% C.I.) and therefore significantly lower compared with E. seguieriana that received flying visitors. Two 'Ants only' plants failed to produce seeds. When all insects were excluded, only $1.6 \pm 1.5 \%$ (mean and $95 \%$ C.I.) of flowers set seed, significantly less than with all other treatments.

Significant differences were also found in the number of fruit capsules in the second year. 'Winged only' treatment resulted in an average $( \pm \mathrm{SE})$ of $97.8 \pm 0.2 \%$, 'Ants only' in $22.7 \pm 1.7 \%$ fruit set per stem (Mann-Whitney $U$ test, $U=0.0, p<0.001$ ). Seeds from 'Winged only' also had a higher germination rate 
267

268

269

270

271

272

273

274

275

276

277

278

279

280

281

282

283

284

compared to 'Ants only' plants (Mann-Whitney $U$ test, $U=0.0, p<0.001$, Fig. 7). All of the 'Winged only' plants produced viable offspring with approximately one third of seeds developing into seedlings. In contrast, only one of the 'Ants only' plant produced offspring (germination rate $6.7 \%$ ). Seeds from all other plants failed to germinate.

\section{Discussion}

This study suggests that ants do not contribute significantly to the reproductive success of $E$. seguieriana. Our findings were somewhat unexpected, because certain aspects suggestive of ant pollination, such as the frequency of ant visits and the proportion of fruit set, had initially indicated otherwise. We found that two ant species were the most frequent visitors of $E$. seguieriana flowers and accounted for two thirds of all recorded insects. A high or very high abundance of ants has been reported as a typical characteristic of ant pollinated plants (e.g. de Vega et al. 2009; Domingos-Melo et al. 2017; Gómez and Zamora 1992; Ibarra-Isassi and Sendoya 2016). Workers of T. erraticum also showed a fairly constant appearance as their visitation rates were neither influenced by time of day nor weather, quite in contrast to winged insects, which were abundant on sunny days but not when it rained. The fact that ants can move between flowers under adverse climatic conditions has been suggested to promote ant pollination as this makes ants more reliable pollen vectors (Gómez 1992; Hickman 1974).

Our observations of nectar-collecting ants indicated that $F$. cunicularia could be a more efficient pollen vector than $T$. erraticum. The former species visited more flowers per observation period and also carried a larger pollen load on its body. However, this notion was contradicted by the fact that only about $10 \%$ of all $F$. cunicularia workers, carried pollen grains that were still viable. Contact with the integument of $T$. erraticum also reduced pollen viability but in this species $43 \%$ of workers carried viable 
290 pollen, thus compensating for the reduced movement between cyathia. Both ants have metapleural

291 glands and it is quite plausible that their secretions were responsible for the adverse effects on pollen

292 viability because viability of pollen from unmanipulated cyathia was significantly higher. Interestingly,

293

294

295

296

297

298

299

300

301

302

303

304

305

306

307

308

309

310

311

312

313

several authors reporting successful ant pollination found that pollen viability was not reduced (Araf et al. 2010; de Vega et al. 2009; Gómez et al. 1996; Ibarra-Isassi and Sendoya 2016; Ramsey 1995), which suggests that resistance of pollen against metapleural gland secretion could be an adapted trait, enabling plants to use ants as pollinators. Alternatively, pollen transfer in the form of pollinia can be regarded as a preadaptation for successful ant pollination too, as this prevents the pollen grains from contact with the metapleural secretion. Ant pollination has been reported in several species of the pollinia-forming families Orchidaceae and Apocynaceae (Domingos-Melo et al. 2017; Peakall and Beattie 1989; Schiestl and Glaser 2012). In Central Europe two orchid species, Coeloglossum viride and Chamorchis alpine, are known to be pollinated by ants (Baumann and Baumann 2010; Claessens and Seifert 2017; Schiestl and Glaser 2012).

Individuals of E. seguieriana grow as bushy, clump-forming perennials with several stems. Ants were frequently observed to move between stems, which can lead to geitonogamy, if pollen are deposited on the stigmata. Since we were interested in the frequency of ants foraging on surrounding spurge plants and hence on the likelihood of outcrossing, a marking experiment was carried out. The obtained results were unambiguous and showed that over a five day period in which the patch was observed for four hours daily, none of the ant workers were recorded anywhere else than on the individual plant on which they were marked at the beginning of the experiment. This high level of micro-site fidelity has also been reported from other plant-ant associations, such as Formica pallidefulva foraging on Euphorbia esula (Fowler 1983) or Camponotus sericeus visiting extrafloral nectaries of the tree Pseudocedrela kotschyi (Mody and Linsenmair 2003), and supports the notion that the occurrence of outcrossing vectored by ants was low in E. seguieriana. 
314 As preliminarily indicated by Rostás and Tautz (2011), excluding ants and/or other groups of pollinating

315 insects from E. seguieriana flowers showed that ants do contribute to fruit set. Compared with plants

316 exposed to winged insects only, however, the ratio of ovules turning into fruits was considerably lower

317 and no difference was found between open pollinated plants and the former. These findings suggest

318 that ants are not necessary for full fruit set and corroborate those of Schürch et al. (2000) made on

319 Euphorbia cyparissias and Blancafort and Gómez (2005) on Euphorbia characias, who likewise question

320 the importance of ants for reproduction when co-occurring with other visitors. Lower fruit set from

321 pollen grains carried by worker ants was likely the consequence of pollen limitation resulting from

322 exposure to the ants' metapleural secretion. Moreover, limitation can also arise from poor pollen quality

323 (Aizen and Vázquez 2006) and it is conceivable that those pollen grains found to be viable may have

324 nevertheless suffered from exposure to the ants' metapleural secretion. Finally, our results also showed

325 that $E$. seguieriana relies on pollinators, because hardly any fruit formation was recorded from

326 completely enclosed plants, supporting the role of protogyny as a mechanism to prevent selfing.

327 More crucial than fruit and seed formation for assessing the true relevance of ants in plant sexual

328 reproduction, however, is the number and performance of offspring (Gómez 2000). In this study we

329 found that ten weeks after sowing, one third of seeds resulting from the 'Winged only' treatment had

330 grown into seedlings, while nearly all seeds obtained from ant pollination had failed to germinate. We

331 hypothesise that pollination by flying insects predominantly led to outcrossing and hence to the

332 production of viable seeds, while ant pollination resulted mostly in geitonogamous, infertile seeds.

333 Inbreeding depression is expressed at various life stages, including seed set, germination, and growth

334 and reproduction of offspring (Angeloni et al. 2011). Both outcrossing and selfing species can be

335 affected, but in outcrossing plants inbreeding depression is generally more pronounced in the first two

336 stages (Husband and Schemske 1996). To our knowledge, seed germination in conjunction with ants as

337 pollinators has only been measured in Lobularia maritima (Brassicaceae) so far (Gómez 2000). In this 
338 species no difference in seedling emergence was found, which could be due to the fact that the plant is

339 self-compatible. Furthermore, frequent visits between individual plants were observed, suggesting a

340 certain level of outcrossing. Seed viability has been assessed, either chemically or morphologically by

341 establishing embryo presence, as an approximation to fitness in two other Mediterranean species

342 (Blancafort and Gómez 2005; de Vega et al. 2009). In both cases no differences were found between ant 343 pollinated plants and controls.

\section{Conclusion}

Flower visitation by ants does not seem to benefit $E$. seguieriana in terms of reproduction and from the

347 plant's perspective may be characterised as neutral, since no cost in fruit set was measured. The plant

348 has not evolved traits to discourage ants, such as repellent floral volatiles (Junker et al. 2011) or

349 inaccessible nectaries, which implies the lack of selection pressure. Nevertheless the interaction could

350 be antagonistic, if undetected costs exist, e.g., should ants reduce the number of offspring by lowering

351 the amount of fertile seeds in open pollinated plants compared with plants visited by flying insects only.

352 This aspect needs further evaluation. Our study reiterates the need for assessing the effect of ant

353 pollinators on fitness parameters beyond seed set to accurately estimate the role of ants in plant 354 reproduction, in particular in outcrossing species.

\section{Acknowledgements}

We thank Dr Gerd Vogg and members of the Botanic Garden for their support. We also thank Michelle

Boyle for critically reading the manuscript. 
360

361

362

363

364

365

366

367

368

369

370

371

372

373

374

375

376

377

378

379

380

381

\section{References}

Aizen MA, Vázquez DP (2006) Flower performance in human-altered habitats. In: Harder LD, Barrett SCH (eds) Ecology and Evolution of Flowers. Oxford University Press, Oxford, pp 159-179

Angeloni F, Ouborg NJ, Leimu R (2011) Meta-analysis on the association of population size and life history with inbreeding depression in plants. Biol Conserv 144:35-43. doi: 10.1016/j.biocon.2010.08.016

Araf M, Kumar S, Hamal IA (2010) Ant pollination of an invasive non-native weed, Euphorbia geniculata Ortega in north west Himalaya (India). The Bioscan 5:81-83

Baskin J, Baskin C (2015) Inbreeding depression and the cost of inbreeding on seed germination. Seed Sci Res 25:355-385. doi: 10.1017/S096025851500032X

Baumann B, Baumann H (2010) Pollination of Chamorchis alpina (L.) Rich. in the Alps by worker ants of Formica lemani Bondroit: first record of ant pollination in Europe. J Eur Orch 42: 3-20.

Beattie AJ (2006) The evolution of ant pollination systems. Botanische Jahrbücher 127:43-55. doi: $10.1127 / 0006-8152 / 2006 / 0127-0043$

Beattie AJ, Turnbull C, Knox RB, Williams EG (1984) Ant inhibition of pollen function - a possible reason why ant pollination is rare. Am J Bot 71:421-426. doi: 10.2307/2443499

Beattie AJ, Turnbull CL, Hough T, Knox RB (1986) Antibiotic production - a possible function for the metapleural glands of ants (Hymenoptera, Formicidae). Ann Entomol Soc Am 79:448-450. doi: 10.1093/aesa/79.3.448

Blancafort X, Gómez C (2005) Consequences of the Argentine ant, Linepithema humile (Mayr), invasion on pollination of Euphorbia characias (L.) (Euphorbiaceae). Acta Oecol 28:49-55. doi: 10.1016/j.actao.2005.02.004 
382 Carvalheiro LG, Barbosa ERM, Memmott J (2008) Pollinator networks, alien species and the conservation

383

384

385

386

387

388

389

390

391

392

393

394

395

396

397

398

399

400

401

402

403

404

of rare plants: Trinia glauca as a case study. J Appl Ecol 45:1419-1427. doi: 10.1111/j.13652664.2008.01518.x

Claessens J, Seifert B (2017) Significant ant pollination in two orchid species in the Alps as adaptation to the climate of the alpine zone? Tuexenia 37:363-374. doi: 10.14471/2017.37.005

Collingwood CA (1979) The Formicidae (Hymenoptera) of Fennoscandia and Denmark. Scandinavian Science Press, Klampenborg, Denmark

de Vega C, Arista M, Ortiz PL, Herrera CM, Talavera S (2009) The ant-pollination system of Cytinus hypocistis (Cytinaceae), a Mediterranean root holoparasite. Ann Bot 103:1065-1075. doi: 10.1093/aob/mcp049

de Vega C, Gómez JM (2014) Polinizacion por hormigas: conceptos, evidencias y futuras direcciones. Ecosistemas 23:48-57. doi: 10.7818/ECOS.2014.23-3.07

Domingos-Melo A, Nadia TdL, Machado IC (2017) Complex flowers and rare pollinators: Does ant pollination in Ditassa show a stable system in Asclepiadoideae (Apocynaceae)? Arthropod Plant Inter 11:339-349. doi: 10.1007/s11829-017-9499-3

Dutton EM, Frederickson ME (2012) Why ant pollination is rare: new evidence and implications of the antibiotic hypothesis. Arthropod Plant Inter 6:561-569. doi: 10.1007/s11829-012-9201-8

Fowler HG (1983) Individual specializations on nectaries of Euphorbia esula by Formica pallidefulva workers. Sociobiology 8:99-104

Gómez JM (2000) Effectiveness of ants as pollinators of Lobularia maritima: effects on main sequential fitness components of the host plant. Oecologia 122:90-97. doi: 10.1007/PL00008840

Gómez JM, Zamora R (1992) Pollination by ants - Consequences of the quantitative effects on a mutualistic system. Oecologia 91:410-418. doi: 10.1007/BF00317631 
405

406

407

408

409

410

411

412

413

414

415

416

417

418

419

420

421

422

423

424

425

426

427

Gómez JM, Zamora R, Hódar JA, García D (1996) Experimental study of pollination by ants in Mediterranean high mountain and arid habitats. Oecologia 105:236-242. doi: 10.1007/BF00328552

Heslop-Harrison J, Heslop-Harrison Y, Shivanna KR (1984) The evaluation of pollen quality, and a further appraisal of the fluorochromatic (Fcr) test procedure. Theor Appl Genet 67:367-375. doi:

10.1007/BF00272876

Hickman JC (1974) Pollination by ants: a low-energy system. Science 184:1290-1292. doi: $10.1126 /$ science. 184.4143 .1290

Hölldobler B, Wilson EO (1990) The Ants. Belknap Press of Harvard University, Cambridge

Husband BC, Schemske DW (1996) Evolution of the magnitude and timing of inbreeding depression in plants. Evolution 50:54-70. doi: 10.2307/2410780

Ibarra-Isassi J, Sendoya SF (2016) Ants as floral visitors of Blutaparon portulacoides (A. St-Hil.) Mears (Amaranthaceae): an ant pollination system in the Atlantic Rainforest. Arthropod Plant Inter 10:221-227. doi: 10.1007/s11829-016-9429-9

Junker RR, Gershenzon J, Unsicker SB (2011) Floral odor bouquet loses its ant repellent properties after inhibition of terpene biosynthesis. J Chem Ecol 37:1323-1331. doi: 10.1007/s10886-011-0043-0

Mody K, Linsenmair KE (2003) Finding its place in a competitive ant community: leaf fidelity of Camponotus sericeus. Insect Soc 50:191-198. doi: 10.1007/s00040-003-0646-8

Novgorodova TA (2015) Organization of honeydew collection by foragers of different species of ants (Hymenoptera: Formicidae): Effect of colony size and species specificity. Eur J Entomol 112:688697: doi: 10.14411/eje.2015.077

Peakall R, Beattie AJ (1989) Pollination of the orchid Microtis parviflora R. Br. by flightless worker ants. Funct Ecol 3:515-522. doi: 10.2307/2389565 
428 Ramsey M (1995) Ant pollination of the perennial herb Blandfordia grandiflora (Liliaceae). Oikos 74:265-

429 272. doi: $10.2307 / 3545656$

430 Rico-Gray V, Oliveira PS (2007) The Ecology and Evolution of Ant-Plant Interactions. The University of

431 Chicago Press, Chicago

432

434

435

436

437

438

439

440

441

442

443

444

445

446

447

448

449

450

451

Dubinsky Z (eds) All Flesh is Grass - Plant-Animal Interrelationships, vol 16. Springer, Dordrecht, pp 151-161

Schaefer M (2000) Fauna von Deutschland: ein Bestimmungsbuch unserer heimischen Tierwelt / Brohmer. Quelle and Meyer, Wiebelsheim

Schiestl FP, Glaser F (2012) Specific ant-pollination in an alpine orchid and the role of floral scent in attracting pollinating ants. Alp Bot 122:1-9. doi: 10.1007/s00035-011-0098-0

Schürch S, Pfunder M, Roy BA (2000) Effects of ants on the reproductive success of Euphorbia cyparissias and associated pathogenic rust fungi. Oikos 88:6-12. doi: 10.1034/j.1600-0706.2000.880102.x

Seifert B (1984) A method for differentiation of the female castes of Tapinoma ambiguum EMERY and Tapinoma erraticum (LATR.) and remarks on their distribution in Europe north of the Mediterranean region. Faunistische Abhandlungen des Staatlichen Museums für Tierkunde in Dresden 11:151-155

Seifert B (1996) Ameisen beobachten, bestimmen. Naturbuch Verlag, Augsburg, Germany

Seifert B (2016) Clypeal excision in Tapinoma Förster, 1850 ants is adaptive (Hymenoptera: Formicidae). Contrib Entomol 66:125-129

Seifert B, Schultz R (2009) A taxonomic revision of the Formica rufibarbis FABRICIUS, 1793 group (Hymeoptera: Formicidae). Myrmec News 12:255-272

Senghas K, Seybold S (2003) Schmeil/Fitschen: Flora von Deutschland und angrenzende Länder, 92 edn. Quelle \& Meyer Verlag, Wiebelsheim, Germany 


\section{Figure 1}

\section{Euphorbia seguieriana}

Siberian spurge, Euphorbia seguieriana subsp. seguieriana, is a perennial forb native to Eurasia. Plants are $15-60 \mathrm{~cm}$ tall with numerous stems. The inflorescence consists of strongly reduced male and female flowers (cyathium).

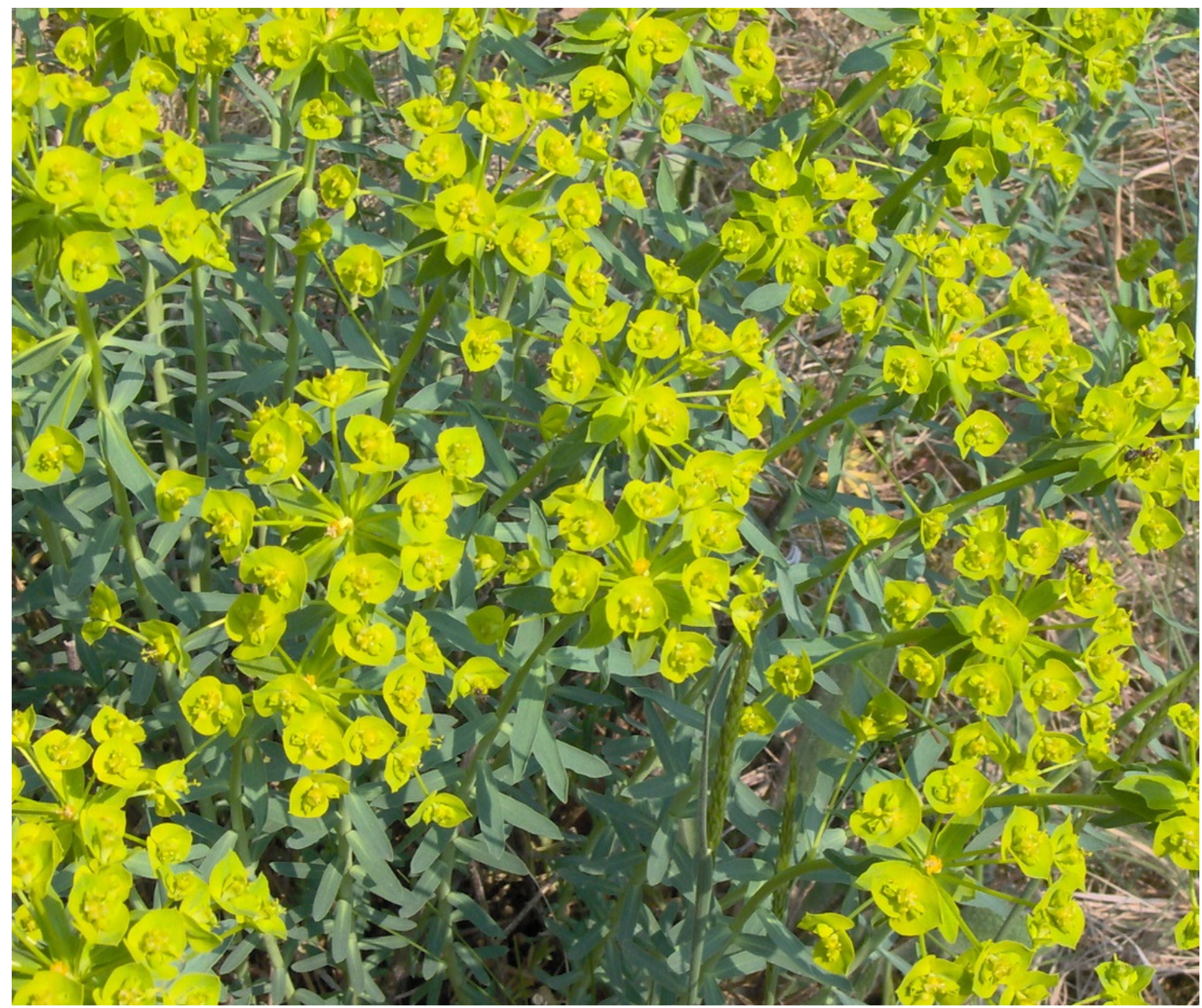


Figure 2

Insect visitors of $E$. seguieriana

Insect visitors of $E$. seguieriana $(n=20)$ during a $10 \mathrm{~d}$ observation period. Flowers were censused twice per day for $1 \mathrm{~h}$. Bars show mean ( \pm s.e.) number of visits per minute. Sampling dates in 2007 are given on the $\mathrm{x}$-axis. Formica $=$ F. cunicularia, Tapinoma $=T$. erraticum, Winged $=$ winged insects.

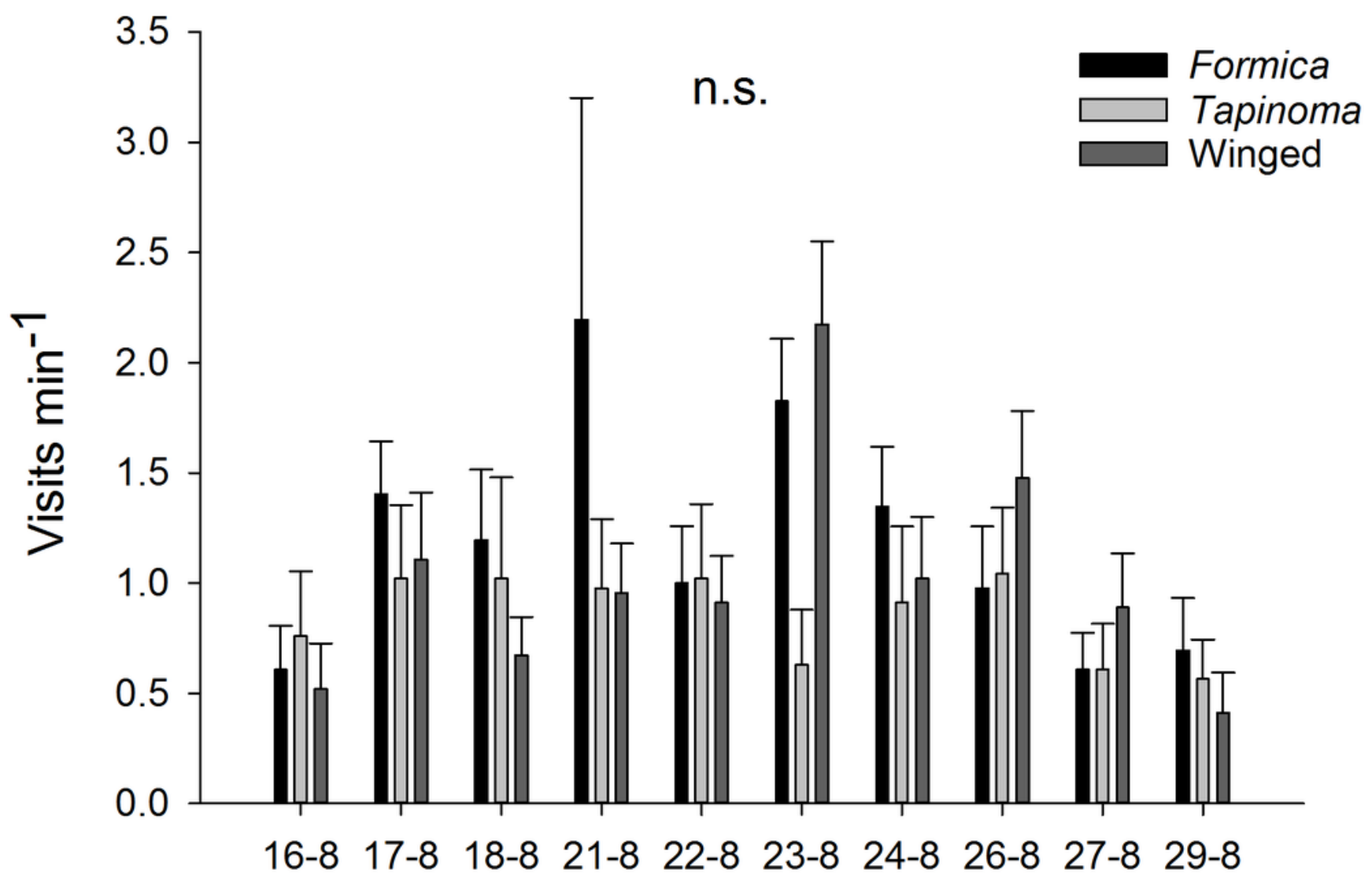




\section{Figure 3 (on next page)}

\section{Daytime and weather effects on flower visitors}

Influence of a daytime and $\mathbf{b}$ weather on insects visiting cyathia of $E$. seguieriana $(n=20)$ during a 10 day observation period. Symbols depict means and $95 \%$ confidence intervals. Formica $=F$. cunicularia, Tapinoma $=T$. erraticum, Winged $=$ winged insects. 

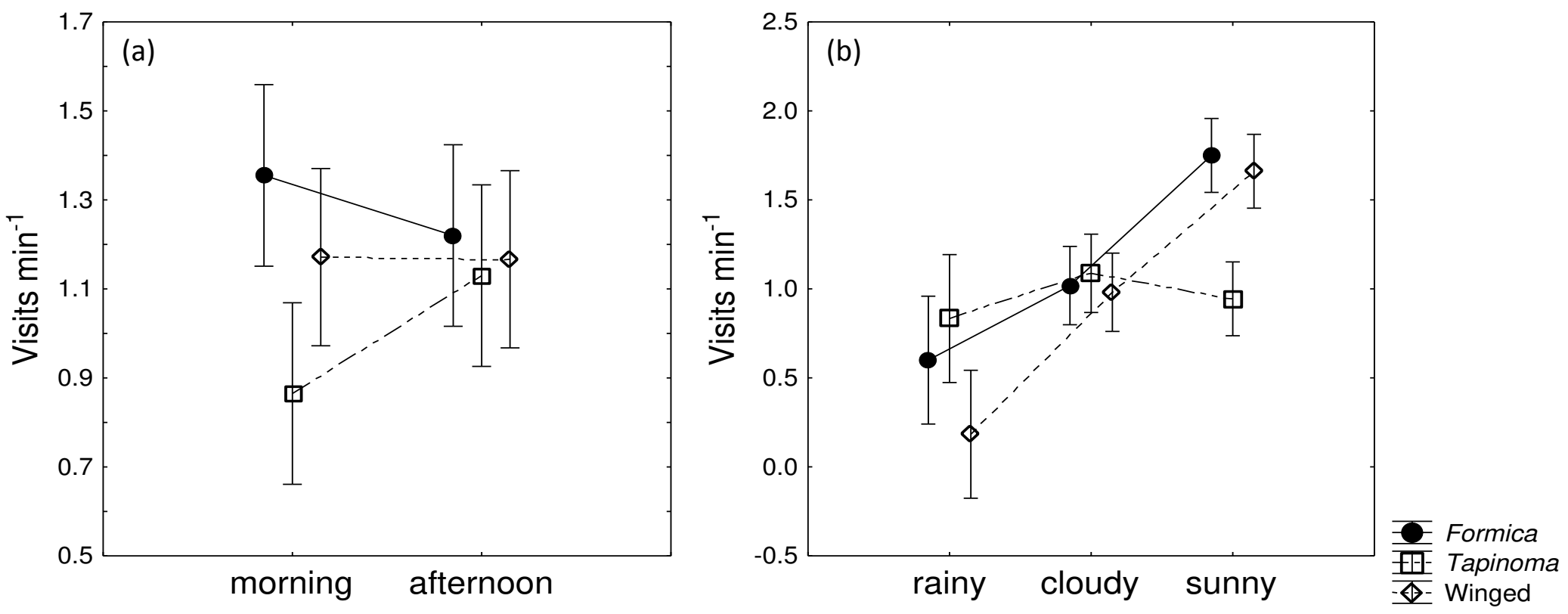
Figure 4

Nectar foraging

a Number of visited cyathia and $\mathbf{b}$ time spent at nectaries by individual ants during a 5 min observation period. Boxes show median (line), $25^{\text {th }}$ and $75^{\text {th }}$ percentiles. Whiskers are $5^{\text {th }}$ and $95^{\text {th }}$ percentiles. Dots show outliers. Formica $=$ F. cunicularia, Tapinoma $=T$. erraticum . Mann-Whitney U test, ${ }^{* * *} \mathrm{p}<0.001$; $\mathrm{n}=30$.

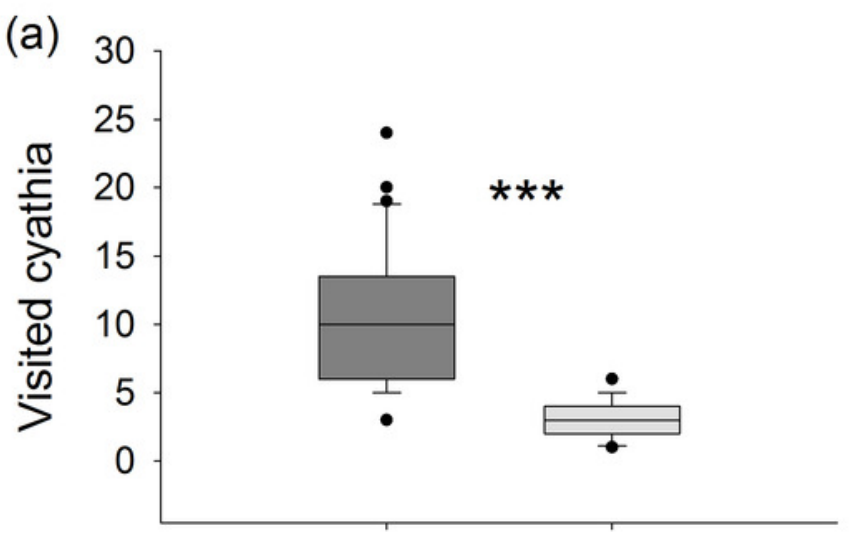

Formica Tapinoma

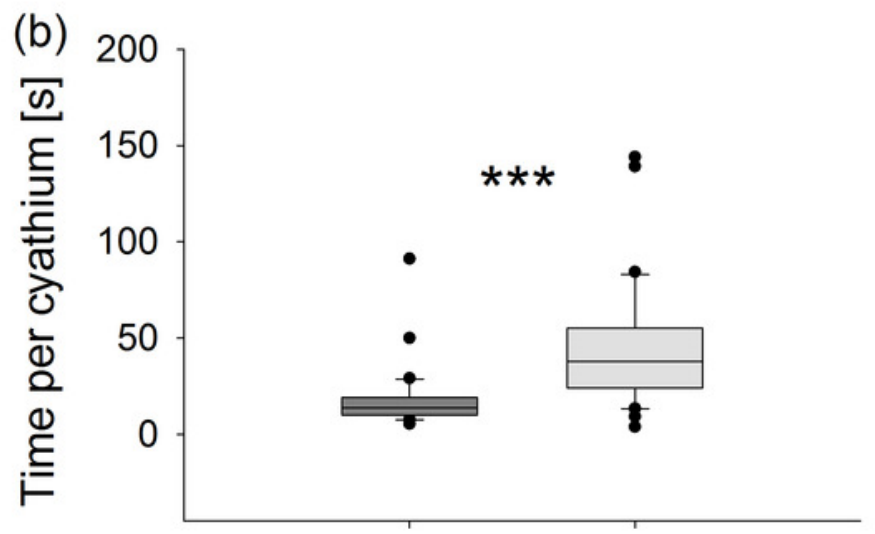

Formica Tapinoma 
Figure 5

Pollen viability

a Number of E. seguieriana pollen grains attached to individual ants. b Number of attached pollen grains that were viable. Boxes show median (line), $25^{\text {th }}$ and $75^{\text {th }}$ percentiles. Whiskers are $5^{\text {th }}$ and $95^{\text {th }}$ percentiles. Dots show outliers. Formica $=F$. cunicularia , Tapinoma $=T$. erraticum . Mann-Whitney U test, ${ }^{*} p<0.05,{ }^{* * *} p<0.001 ; \mathrm{n}=30$.

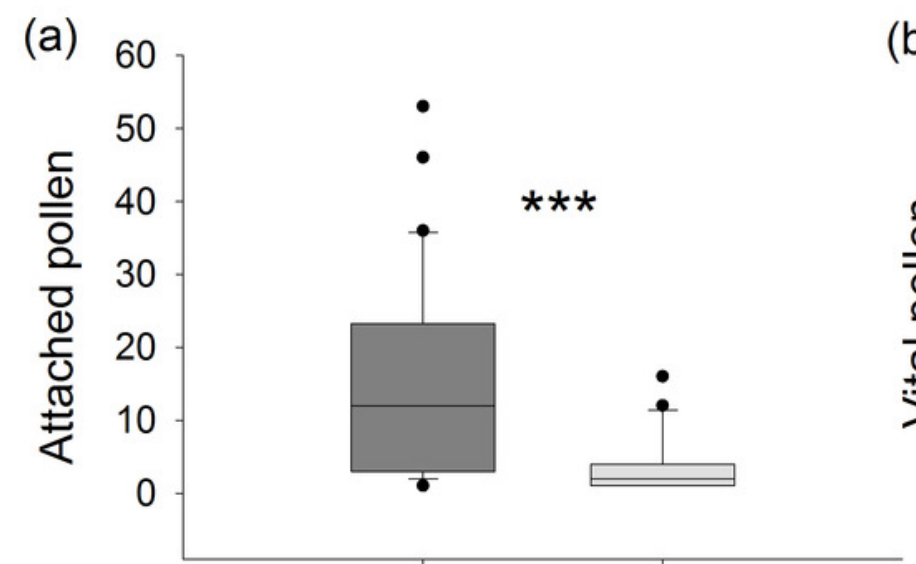

Formica Tapinoma (b) 60

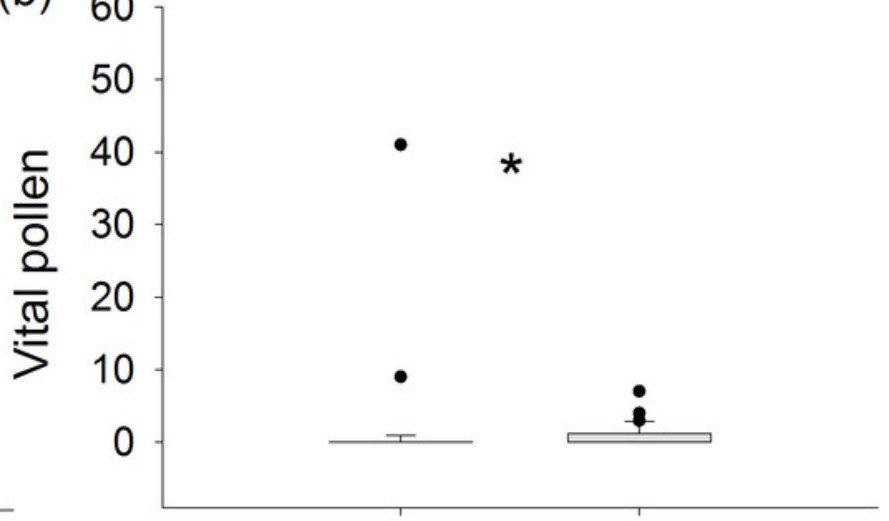

Formica Tapinoma 


\section{Figure 6}

Fruit set

Female fertility of $E$. seguieriana measured as percentage of fruit set. All insects $=$ open pollinated plants, Ants $=$ flower access restricted to ants, Winged $=$ flower access restricted to flying insects, No insects = flowers completely enclosed. Boxes show median (line), 25 th and $75^{\text {th }}$ percentiles. Whiskers are $5^{\text {th }}$ and $95^{\text {th }}$ percentiles. Dots show outliers. Different letters indicate significant differences based on the comparison of $95 \%$ confidence intervals (alpha $=0.05) ; \mathrm{n}=10$.

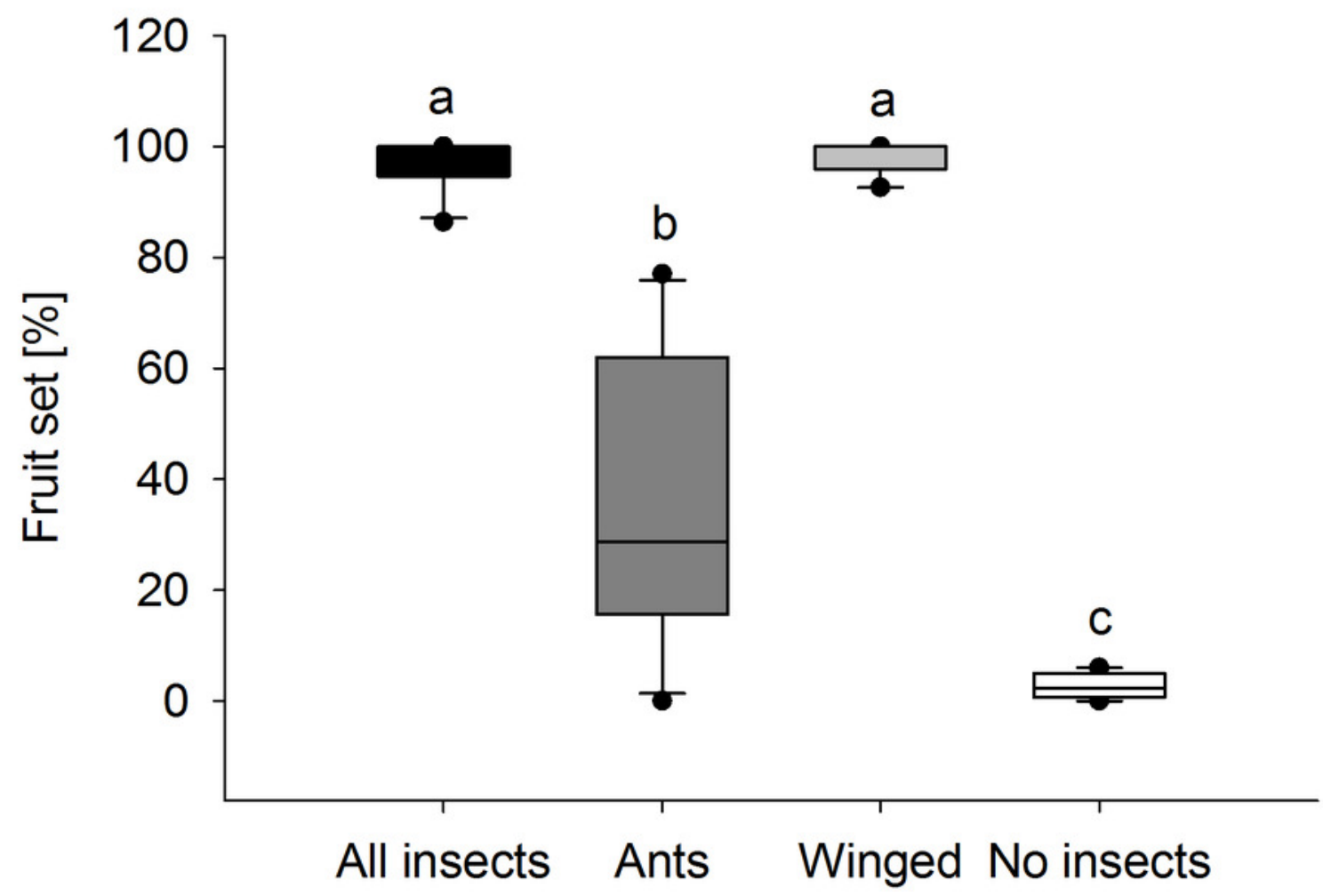


Figure 7

Seedling emergence

Germination rate of $E$. seguieriana seeds produced by plants that were pollinated by winged insects and ants, respectively. Boxes show median (line), $25^{\text {th }}$ and $75^{\text {th }}$ percentiles. Whiskers are $5^{\text {th }}$ and $95^{\text {th }}$ percentiles. Dots show outliers. Mann-Whitney $U$ test, ${ }^{* * *} p<$ $0.001, n=9-10$.

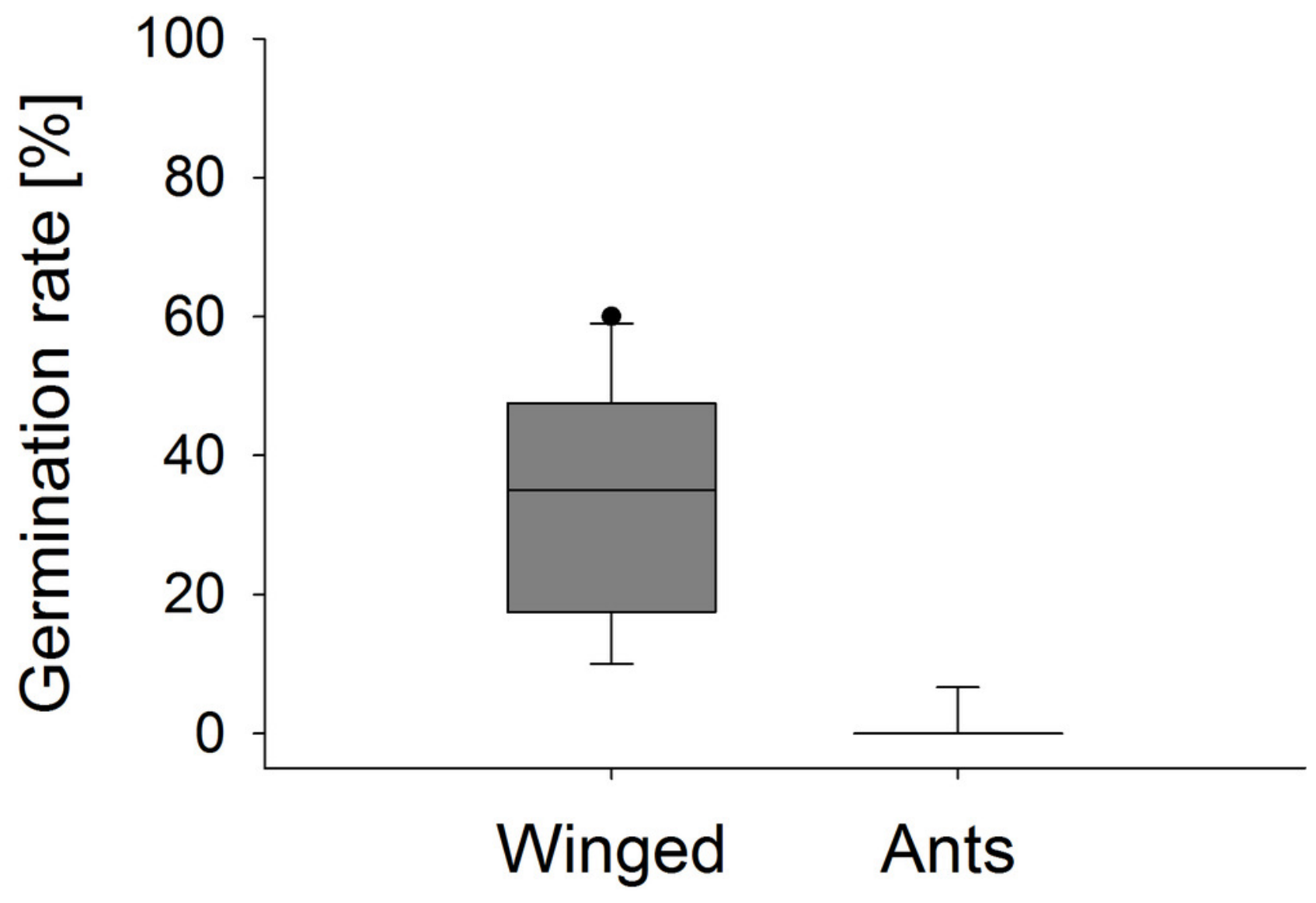

